\title{
Reduced Container Volume Increases Tomato Pollen Fertility at Low Ambient Temperatures
}

\author{
Eva Domínguez, Jesús Cuartero, and Rafael Fernández-Muñoz ${ }^{1}$ \\ Estación Experimental La Mayora, Consejo Superior de Investigaciones Científicas, E-29750 Algarrobo- \\ Costa (Málaga), Spain
}

\begin{abstract}
AdDITIONAL INDEX wORDS. Lycopersicon esculentum, L. pennellii, in vitro germination, acetocarmine staining, pollen quantity, in vivo pollen tube growth, root-zone temperature

Aвstract. Using soil bed cultivations as controls and under two temperature regimes (maximum/minimum $\approx 20 / 4{ }^{\circ} \mathrm{C}$ and $25 /$ $\left.10^{\circ} \mathrm{C}\right)$, effects of container volume (16-, 10-, and 3-L pots) on in vitro germination, in vivo tube growth, acetocarmine staining, and quantity of pollen of tomato [Lycopersicon esculentum Mill. 'Moneymaker', L. pennellii (Corr.) D'Arcy accession PE45 , and of the corresponding $F_{1}$ hybrid] were studied. Under the $20 / 4{ }^{\circ} \mathrm{C}$ regime, in comparison with soil-bed cultivated control plants, the cold sensitive cultivar, Moneymaker, grown in the two smaller pots showed significant increases of in vitro pollen germination, acetocarmine staining, and number of pollen grains produced per flower. Similar results were observed with the $F_{1}$ except for the number of pollen grains which were not significantly different. Pollen of accession PE-45 was unaffected by cold and no container effect was detected. Results of in vivo pollen tube growth in 'Moneymaker' at the 20/ $4{ }^{\circ} \mathrm{C}$ regime showed that fruit set was only possible in 3-L pots. Reduction of the negative effects of cold on pollen from plants grown in the 3-L pots may be explained in part by the daytime rise of root-zone temperatures that did not occur in the 10or 16-L pots or in the soil bed. Therefore, fruit production of tomato plants grown under low temperatures in small pots may not be a valid predictor of commercial winter fruit production of plants cultivated in soil beds.
\end{abstract}

Temperatures $<10^{\circ} \mathrm{C}$ permit vegetative growth of tomato (Lycopersicon esculentum Mill.) plants but they greatly decrease the number of fruit per plant (for a review, see Picken, 1984). In winter cultivation in temperate areas, this decrease in fruit set is caused mainly by reduced pollen viability and by failure of pollen release from the anthers when night temperatures are low. Poor fruit set at low night temperatures $\left(\approx 6{ }^{\circ} \mathrm{C}\right)$ is not caused by reduced ovule viability or early interruption of embryo development (FernándezMuñoz and Cuartero, 1991).

Fruit set under adverse conditions is a very complex phenomenon that includes many other traits closely associated with reproductive structures and events (pollen and ovule viability, effective pollination, and early fruit development) and these in turn may be influenced by several vegetative physiological traits. Moreover, each single reproductive event may have polygenic control. For example, viability of pollen formed at low temperatures in crosses of a sensitive tomato cultivar with a tolerant accession of a wild tomato species seems to be controlled by three loci (FernándezMuñoz et al., 1995b). Genetic studies of such environmentally influenced characters are more effective if experiments are carried out under controlled conditions. Many published studies on fruiting of horticultural crops in controlled environments do not consider container size and, in fact, pot sizes are usually chosen to accommodate the number of plants needed for the experiment and to fit the limited space available in the growth chamber or greenhouse.

In previous experiments, we noted that fruit set of tomato plants grown under regimes of low night temperatures in pots versus fruit set of plants in soil beds seemed to differ. Plants grown in soil beds were more sensitive to low night temperatures $\left(\approx 6^{\circ} \mathrm{C}\right)$ than those

\footnotetext{
Received for publication 9 Aug. 2000. Accepted for publication 11 Sept. 2001 We gratefully acknowledge financial support for this study by the Spanish FEDER-CICYT Project 1FD97-0620-CO2-01. We thank David W. Schofield for helpful suggestions while translating the manuscript. Use of trade names in this publication does not imply endorsement by the Consejo Superior de Investigaciones Científicas of products named nor criticism of similar ones not mentioned. The cost of publishing this paper was defrayed in part by the payment of page charges. Under postal regulations, this paper therefore must be hereby marked advertisement solely to indicate this fact.

'Corresponding author; e-mail: rfern@eelm.csic.es.
}

grown in pots and this was reflected in the lower number of fruit produced (unpublished results). There are reports about the influence of physical constraints for root growth by small volume containers that, in turn, affect vegetative physiological characters of tomato plants (Bar-Tal et al., 1995; Cooper, 1972; Hameed et al., 1987; Nishizawa and Saito, 1998; Peterson et al., 1991a,b; Ruff et al., 1987) and also of other plant species (Boland et al. 2000a,b; Krizek et al. 1985; Liu and Latimer, 1995; Reiger and Marra, 1994; Robbins and Pharr, 1988). Boland et al. (2000a,b) hypothesize that, generally, root restriction limits vegetative growth, but does not negatively affect fruiting efficiency and Bar-Tal and Pressman (1996) found that the effect of root restriction on slightly reduced tomato fruit yield was greater than its effect on reduction in fruit number. Nevertheless, not much appears to be known about the effects of root restriction on the several reproductive characters known to determine fruit set.

However, if container size (actually volume) does affect any of the characters known to be associated with fruiting, such as quality or quantity of pollen produced under adverse conditions, results of some of studies that are carried out using pots will not apply to commercial crops usually cultivated in soil beds. Therefore, the present research was designed to study the effects of substrate volumes available for root development on the quality and quantity of tomato pollen produced under two low-temperature regimes. To study the possible interaction effects between container volume and low-temperature sensitivity, we used a tomato cultivar, a coldtolerant, wild species accession, and their $\mathrm{F}_{1}$ hybrid.

\section{Materials and Methods}

Plant material and environments. The tomato cultivar, Moneymaker, L. pennellii (Corr.) D'Arcy accession PE-45, a wild species, and their $F_{1}$ hybrid were used. 'Moneymaker' was chosen for relatively poor pollen viability at low temperatures and PE- 45 for cold tolerance (Fernández-Muñoz et al., 1995a). Two experiments were carried out during February to March 1997. One experiment used plants in a temperature-controlled glasshouse in which a refrigeration unit functioned during the night to ensure a minimum 
night temperature of $\approx 4^{\circ} \mathrm{C}$. Plants of the other experiment were cultivated in a polyethylene greenhouse without temperature control. Four plants per genotype per treatment were grown in each experiment. Plants were grown in soil beds and in 16-, 10-, and 3$\mathrm{L}$ polyethylene pots. Depth of the soil beds was $50 \mathrm{~cm}$. Heights of the 16-, 10-, and 3-L pots were 25, 22, and $14 \mathrm{~cm}$, respectively. Beds and pots had the same soil substrate. Comprised $22 \%$ clay, $24 \%$ silt, and $54 \%$ sand. Plants were watered as needed to maintain proper soil moisture and care was taken to avoid any drought stress. Plants were fertilized every other week with half-strength Hoagland's nutrient solution (Hoagland and Arnon, 1950).

Plants were trained to two stems to allow more flowers per plant to be open at the same time. Pollen was sampled from young plants: samplings started when most plants had open flowers at the first inflorescence of the secondary stem. Pollen produced by each plant was collected on 4 Mar., 10 Mar., and 18 Mar. in the refrigerated glasshouse experiment and on 4 Feb., 25 Feb., and 11 Mar. in the polyethylene greenhouse experiment. According to Mutton et al. (1987) the deleterious effects of cold on tomato pollen formation appear mainly when low temperatures are applied on the days 4, 5, $6,12,13$, or 14 before anthesis. The average air temperatures recordered on these six thermosensitive days for each sampling date for both experiments are presented in Table 1. Averages of daily maximum/minimum air temperatures were $20.6 \pm 2.3 / 3.9 \pm 0.5^{\circ} \mathrm{C}$ during the experiment in the refrigerated glasshouse and $25.5 \pm 3.5 /$ $10.5 \pm 1.0^{\circ} \mathrm{C}$ during the experiment in the polyethylene greenhouse. Based upon these, the two experiments were referred to as the 20/ $4{ }^{\circ} \mathrm{C}$ and $25 / 10{ }^{\circ} \mathrm{C}$ temperature regimes. In the refrigerated glasshouse experiment, the minimum night air temperatures were always much lower than $10^{\circ} \mathrm{C}$ and, consequently, it represents the experimental low temperature treatment. At these low temperatures, we expected that the cold sensitive plants would produce pollen with reduced fertility (Charles and Harris, 1972; Maisonneuve, 1982). The minimum night temperatures in the polyethylene greenhouse experiment were around the reported threshold of cold effect on pollen and this experiment typifies the usual off-season cultivation of tomato in many production areas of the world generally resulting in successful production. Since root temperatures were suspected to be a determining factor involved in any container-volume effect, soil temperatures at a $12 \mathrm{~cm}$ depth in the substrate in each of the four volume treatments in the two experiments were measured first $1 \mathrm{~h}$ after sunrise $(\approx 0900 \mathrm{HR})$ and then, second, when the air temperatures started to decline in the greenhouses $(\approx 1400 \mathrm{HR})$. Differences in pollen fertility were not expected to be caused by other environmental parameters such as relative humidity $(\mathrm{RH})$ or irradiance because these were similar in the two experiments. Average daily maximum, mean, and minimum RH were $86.6 \pm 3.1 \%, 72.7 \pm 2.4 \%$, and 56.0 $\pm 6.0 \%$, respectively, for the $20 / 4{ }^{\circ} \mathrm{C}$ regime and $91.9 \pm 3.3 \%, 78.8$ $\pm 5.2 \%$ and $63.6 \pm 10.5 \%$, respectively, for the $25 / 10^{\circ} \mathrm{C}$ regime. Average daily integrated photosynthetic photon flux was $19.6 \pm 3.8$ $\mathrm{mol} \cdot \mathrm{m}^{-2} \cdot \mathrm{d}^{-1}$ for the $20 / 4^{\circ} \mathrm{C}$ regime and, $17.9 \pm 6.1 \mathrm{~mol} \cdot \mathrm{m}^{-2} \cdot \mathrm{d}^{-1}$ for the $25 / 10^{\circ} \mathrm{C}$ regime. The environmental data were recorded continuously by a data logger equipped with a temperature/RH probe (model 41372/43372; R.M. Young Co., Traverse City, Mich.), and a quantum sensor (LI-190SA; LI-COR, Inc., Lincoln, Nebr.). Temperatures in the root zone were measured with a standard thermometer.

ASSESSMENTS OF POLLEN GERMINATION, VIABILITY, AND QUANTITY. Pollen fertility was evaluated by in vitro germination, the standard laboratory reference method to estimate pollen quality when a wellsuited germination medium is available (Shivanna and Johri, 1985). Pollen viability was estimated by acetocarmine staining because this method, which measures the proportion of pollen grains that do not abort, is appropriate to estimate viability of tomato pollen formed at low temperatures (Fernández-Muñoz et al., 1994). In addition, fertility of 'Moneymaker' pollen was assessed by observing pollen tube growth in vivo, a very reliable technique that correlated quite well with the number of seeds per fruit produced by tomato plants after a cold treatment (Fernández-Muñoz et al., 1994).

The number of pollen tubes in the styles was counted only for 'Moneymaker' because problems of self-incompability occur in the styles of the wild accession and the $\mathrm{F}_{1}$. Pollen quantity can be calculated reliably in tomato by weighing the pollen liberated from anthers of a known number of flowers (Maisonneuve and Philouze, 1982) but this method requires too many flowers for experiments like the present study. Instead, the number of pollen grains produced per flower was estimated by counting pollen grains on clinical haemacytometer grids. A pollen sample for each combination of plant $\times$ genotype $\times$ container volume $\times$ temperature regime $\times$ sample date was taken. Each sample was a mixture of pollen from five flowers of the same plant at anthesis. Pollen was collected by vigorously shaking the anthers with a needle over a microtube. Then, $1.5 \mathrm{~mL}$ of germination medium [15\% sucrose, $1.27 \mathrm{~mm}$ $\mathrm{Ca}\left(\mathrm{NO}_{3}\right)_{2}, 1.62 \mathrm{~mm} \mathrm{H}_{3} \mathrm{BO}_{3}, 1 \mathrm{~mm} \mathrm{KNO}_{3}$, and $\left.0.1 \mathrm{~mm} \mathrm{KH}_{2} \mathrm{PO}_{4}\right]$ was pipetted into the microtube. Immediately after homogenization, 1 $\mathrm{mL}$ was pipetted into a $4 \mathrm{~mL}$ assay tube, the tube was capped, and then incubated on a shaker at $25^{\circ} \mathrm{C}$ for $12 \mathrm{~h}$. The contents were stained and fixed by adding $200 \mu \mathrm{L}$ of a $1 \%$ acetocarmine solution. Each pollen sample was assessed by inspecting more than 200 grains in at least five microscope fields to calculate the percentage of pollen grains germinated in vitro. Before pollen germination, 200 $\mu \mathrm{L}$ of the $1 \%$ acetocarmine solution was added to the remaining 0.5 $\mathrm{mL}$ in the microtube to calculate pollen viability by counting the percentage of pollen grains stained by acetocarmine. Number of pollen grains liberated from the anthers of a single flower was estimated by counting pollen grains on the grids of two FuchsRosenthal clinical haemacytometers (E. Hartnack, Berlin, Germany) and averaging them. To inspect and measure 'Moneymaker' in vivo pollen tube growth, two to four flowers which were at the receptive stage on each plant were hand-pollinated in excess with a mixture of pollen from the open flowers of all the plants of the same treatment. After $24 \mathrm{~h}$, styles were cut at the base and fixed for $24 \mathrm{~h}$ in a solution (90:5:5) of 50\% ethanol : acetic acid : formalin. The pollen tubes were stained and inspected according to Martin (1959) and the number of pollen tubes that had reached half-length and the end of each style were counted.

Data ANALYSIS. Statistical analyses were performed using the Statistical Package for Social Sciences, Release 9.0.1 software (SPSS, 1999). Before statistical analyses, the percentages of pollen germination and viability were transformed to the arcsine of the square root for normality. However the data presented are nontransformed. Separate fixed-effects analyses of variance of temperature regime $\times$ substrate volume with type III sums of squares were conducted for each genotype for acetocarmine staining, in vitro germination, and number of pollen grains. One-way analyses of variance of substrate volume were performed for number of pollen tubes at half and the base of the style of 'Moneymaker' plants. Student-Newman-Keuls (SNK) multiple range test (Sokal and Rohlf, 1981) was used to compare treatment means.

\section{Results}

Despite observed differences between minimum and maximum daily temperatures (Table 1), air temperatures in the two green- 
Table 1. Averages \pm SDs of the maximum, mean, and minimum air temperatures recorded in the 6 thermosensitive days [days $4,5,6,12,13$, and $14 \mathrm{~d}$ identified by Mutton et al. (1987) before each sampling date] in the two experiments.

\begin{tabular}{|c|c|c|c|c|}
\hline \multirow[b]{2}{*}{ Experiment } & \multirow[b]{2}{*}{ Sampling date } & \multicolumn{3}{|c|}{ Air temp $\left({ }^{\circ} \mathrm{C}\right)$} \\
\hline & & Max & Mean & Min \\
\hline \multirow[t]{3}{*}{ Refrigerated glasshouse } & 4 Mar. & $21.7 \pm 0.9$ & $11.4 \pm 0.1$ & $3.8 \pm 0.2$ \\
\hline & 10 Mar. & $19.0 \pm 3.7$ & $10.1 \pm 2.0$ & $3.7 \pm 0.5$ \\
\hline & 18 Mar. & $21.0 \pm 0.4$ & $11.5 \pm 0.3$ & $4.2 \pm 0.8$ \\
\hline \multirow[t]{3}{*}{ Polyethylene greenhouse } & 4 Feb. & $22.1 \pm 3.6$ & $14.2 \pm 1.6$ & $10.4 \pm 1.7$ \\
\hline & 25 Feb. & $27.6 \pm 1.8$ & $17.1 \pm 0.3$ & $10.3 \pm 0.5$ \\
\hline & 11 Mar. & $26.8 \pm 2.6$ & $17.6 \pm 0.8$ & $10.8 \pm 0.7$ \\
\hline
\end{tabular}

houses were very similar at the times when root temperatures were measured (0900 and $1400 \mathrm{HR}$ ) (Table 2). At 0900 HR root temperatures in the refrigerated glasshouse experiment $\left(20 / 4^{\circ} \mathrm{C}\right.$ regime) were $\approx 10^{\circ} \mathrm{C}$ or less, while in the polyethylene greenhouse experiment $\left(25 / 10{ }^{\circ} \mathrm{C}\right.$ regime) they were clearly above $10^{\circ} \mathrm{C}$ (Table 2$)$. Under the $20 / 4{ }^{\circ} \mathrm{C}$ regime, the differences between root temperature at 0900 and $1400 \mathrm{HR}$ were inversely proportional to container volume, and this reflects the buffering capacity of larger container volumes (Table 2). Those differences appeared to be the result of the dramatic increase in root temperatures during the day, especially of those plants in the smallest pots. In both experiments, maximum substrate temperatures in the 3-L pots during the day (Table 2) were even higher than the maximum air temperatures (Table 1).

Differences in pollen quality or quantity at the three sampling dates were not significant (data not presented), so, data from the samples were pooled. Pollen of the cold sensitive cultivar, Moneymaker, was negatively affected by low temperatures because the overall means of percentage in vitro germination, percentage acetocarmine staining, and numbers of pollen grains per flower were significantly less at the $20 / 4{ }^{\circ} \mathrm{C}$ regime than those of the $25 /$ $10{ }^{\circ} \mathrm{C}$ regime (Fig. 1). This negative effect was particularly marked for numbers of pollen grains, which at $25 / 10^{\circ} \mathrm{C}\left(\right.$ mean $=23.9 \times 10^{3}$ grains) was double that at $20 / 4^{\circ} \mathrm{C}\left(\right.$ mean $=11.0 \times 10^{3}$ grains $)$. The tolerant accession, PE-45, was unaffected by cold because no significant differences of the two temperature regimes were found for pollen fertility (in vitro germination), pollen viability (acetocarmine staining), or pollen quantity. The response to cold of the $F_{1}$ was intermediate between the responses of the parents because pollen viability was lower at $20 / 4{ }^{\circ} \mathrm{C}$ than at $25 / 10{ }^{\circ} \mathrm{C}$ (sensitive performance), while pollen fertility and pollen quantity were similar at both temperature regimes (tolerant performance). It was noteworthy, and most surprising, that 'Moneymaker' pollen at the two temperature regimes germinated better in vitro than pollen of PE-45 and the $F_{1}$. The number of pollen grains was higher for PE45 than for 'Moneymaker' and, for the $\mathrm{F}_{1}$, the number of pollen grains was intermediate.

Larger container volumes significantly reduced 'Moneymaker' pollen fertility, pollen viability, and pollen quantity under the 20/ $4{ }^{\circ} \mathrm{C}$ regime. The numbers of pollen grains produced per flower of 'Moneymaker' plants in the soil bed and, to a lesser extent, those produced by flowers from plants in the $16-\mathrm{L}$ pots were less than those from plants cultivated in the 10- or 3-L pots (Fig. 1). At higher temperatures $\left(25 / 10^{\circ} \mathrm{C}\right.$ regime), no effect of pot size on in vitro germination and acetocarmine staining was found, however, pollen quantity of the plants cultivated in the 3 - and 10-L pots was higher than that of plants cultivated in soil beds. This result is similar to that found with the $20 / 4{ }^{\circ} \mathrm{C}$ regime. For the $\mathrm{F}_{1}$ at the $20 / 4{ }^{\circ} \mathrm{C}$ regime, container volume produced clear differences only for pollen fertility: in vitro pollen germination of plants grown in the soil bed was significantly lower than that of any of the potted plants. Acetocarmine staining and number of pollen grains were affected little or not at all by container volume. No effect of container volume was detected for the $\mathrm{F}_{1}$ at the $25 / 10{ }^{\circ} \mathrm{C}$ regime. The cold tolerant accession, PE- 45 , under the $20 / 4{ }^{\circ} \mathrm{C}$ regime showed no significant differences for pollen germination, pollen staining, or pollen quantity. At $25 / 10^{\circ} \mathrm{C}$, the only significant effect was that in vitro pollen germination of plants grown in soil beds were higher than that of flowers from plants grown in the 16- and 10-L pots.

The effect of cold on pollen quality and quantity of cold-sensitive plants grown in the smallest pots was masked. In other words, comparisons between percentage in vitro germination, percentage acetocarmine staining, and number of pollen grains per flower of 'Moneymaker' plants grown in 3 -L pots at the $20 / 4{ }^{\circ} \mathrm{C}$ regime, and those of 'Moneymaker' plants grown in the soil bed under the 25/

Table 2 . Averages \pm SDs of temperatures in the air and at $12 \mathrm{~cm}$ depth in the substrate for the different pot volumes and for the soil bed in the two experiments, measured $1 \mathrm{~h}$ after sunrise ( $0900 \mathrm{HR}$ ) and at the time when air temperature began to decline in the greenhouses (1400 HR), and temperature difference between 0900 and $1400 \mathrm{HR}(\Delta \mathrm{T})$.

\begin{tabular}{|c|c|c|c|c|c|}
\hline \multirow{3}{*}{$\begin{array}{l}\text { Temp } \\
\text { regime }\end{array}$} & \multirow{3}{*}{$\begin{array}{c}\text { Air } \\
\text { temp } \\
\left({ }^{\circ} \mathrm{C}\right)\end{array}$} & \multicolumn{4}{|c|}{ Pot vol } \\
\hline & & $3 \mathrm{~L}$ & $10 \mathrm{~L}$ & $16 \mathrm{~L}$ & Soil bed \\
\hline & & \multicolumn{4}{|c|}{ Substrate temp $\left({ }^{\circ} \mathrm{C}\right)$} \\
\hline \multicolumn{6}{|l|}{$20 / 4{ }^{\circ} \mathrm{C}$} \\
\hline $0900 \mathrm{HR}$ & $14.0 \pm 0.9$ & $8.0 \pm 0.5$ & $7.0 \pm 0.2$ & $7.8 \pm 0.3$ & $10.0 \pm 0.2$ \\
\hline $1400 \mathrm{HR}$ & $19.3 \pm 1.8$ & $23.0 \pm 2.4$ & $19.3 \pm 3.2$ & $16.5 \pm 1.7$ & $12.5 \pm 0.7$ \\
\hline$\Delta \mathrm{T}$ & 5.3 & 15.0 & 12.3 & 8.7 & 2.5 \\
\hline \multicolumn{6}{|l|}{$25 / 10^{\circ} \mathrm{C}$} \\
\hline $0900 \mathrm{HR}$ & $13.5 \pm 2.1$ & $13.5 \pm 0.7$ & $13.5 \pm 0.8$ & $13.5 \pm 0.7$ & $16.0 \pm 1.4$ \\
\hline $1400 \mathrm{HR}$ & $20.5 \pm 2.7$ & $27.5 \pm 3.5$ & $18.0 \pm 2.8$ & $18.0 \pm 2.4$ & $20.0 \pm 2.8$ \\
\hline$\Delta \mathrm{T}$ & 7.0 & 14.0 & 4.5 & 4.5 & 4.0 \\
\hline
\end{tabular}


$10{ }^{\circ} \mathrm{C}$ regime (the representative for normal off-season commercial tomato cultivation), were not significant.

Hand pollination of 'Moneymaker' flowers demonstrated that at $20 / 4{ }^{\circ} \mathrm{C}$ only the plants grown in 3 -L pots produced flowers with pollen able to grow a few pollen tubes and reach the base of the style (Table 3). Pollen grains from plants cultivated in the larger pots and in the soil bed even failed to germinate on the stigma (data not presented). In contrast, in the $25 / 10^{\circ} \mathrm{C}$ regime, the pollen tubes reached the base of the style of flowers of the plants grown in all four containers. With an increase in container volume, there tended to be an increase in number of pollen tubes that reached half-length and the base of the style.

\section{Discussion}

Inheritance of sensitivity of tomato pollen formed at low temperatures in interspecific crosses of L. esculentum $\times$ L. pennellii is reported to be intermediate between the parents (Fernández-Muñoz et al., 1995b). Consequently, pollen germination, acetocarmine stainability, and pollen quantity produced under low night temperatures should be high in PE-45, intermediate in the $F_{1}$ hybrid, and low in the sensitive cultivar, Moneymaker. This trend was confirmed by pollen staining and, particularly, by number of pollen grains per flower. However, the overall in vitro germination percentages obtained in the present study were higher for 'Moneymaker' than for $\mathrm{PE}-45$ and the $\mathrm{F}_{1}$ hybrid. This result could be explained because we optimized the germination medium for L. esculentum but not for the wild species. Further studies in which the composition of the medium was modified resulted in germination percentages around $55.6 \%$ for $\mathrm{PE}-45\left[20 \%\right.$ sucrose, $1.27 \mathrm{~mm} \mathrm{Ca}\left(\mathrm{NO}_{3}\right)_{2}, 1.62 \mathrm{~mm} \mathrm{H}_{3} \mathrm{BO}_{3}$, $1 \mathrm{mM} \mathrm{KNO}_{3}$, and $\left.0.1 \mathrm{mM} \mathrm{KH}_{2} \mathrm{PO}_{4}\right]$ and $33 \%$ for the $\mathrm{F}_{1}$ hybrid $[20 \%$ sucrose, $0.32 \mathrm{~mm} \mathrm{Ca}\left(\mathrm{NO}_{3}\right)_{2}, 3.25 \mathrm{~mm} \mathrm{H}_{3} \mathrm{BO}_{3}, 1 \mathrm{~mm} \mathrm{KNO}_{3}$, and 0.1 $\mathrm{mm} \mathrm{KH}_{2} \mathrm{PO}_{4}$ ] when plants were grown in soil beds at $25 / 10^{\circ} \mathrm{C}$. These germination percentages agree better with the expected results.

The number of pollen grains per flower seems to be an important restrictive character of fruit setting in winter because, in both temperature regimes, 'Moneymaker' produced less than 30,000

\section{In vitro germination}

\section{Acetocarmine staining}

Pollen grains per flower
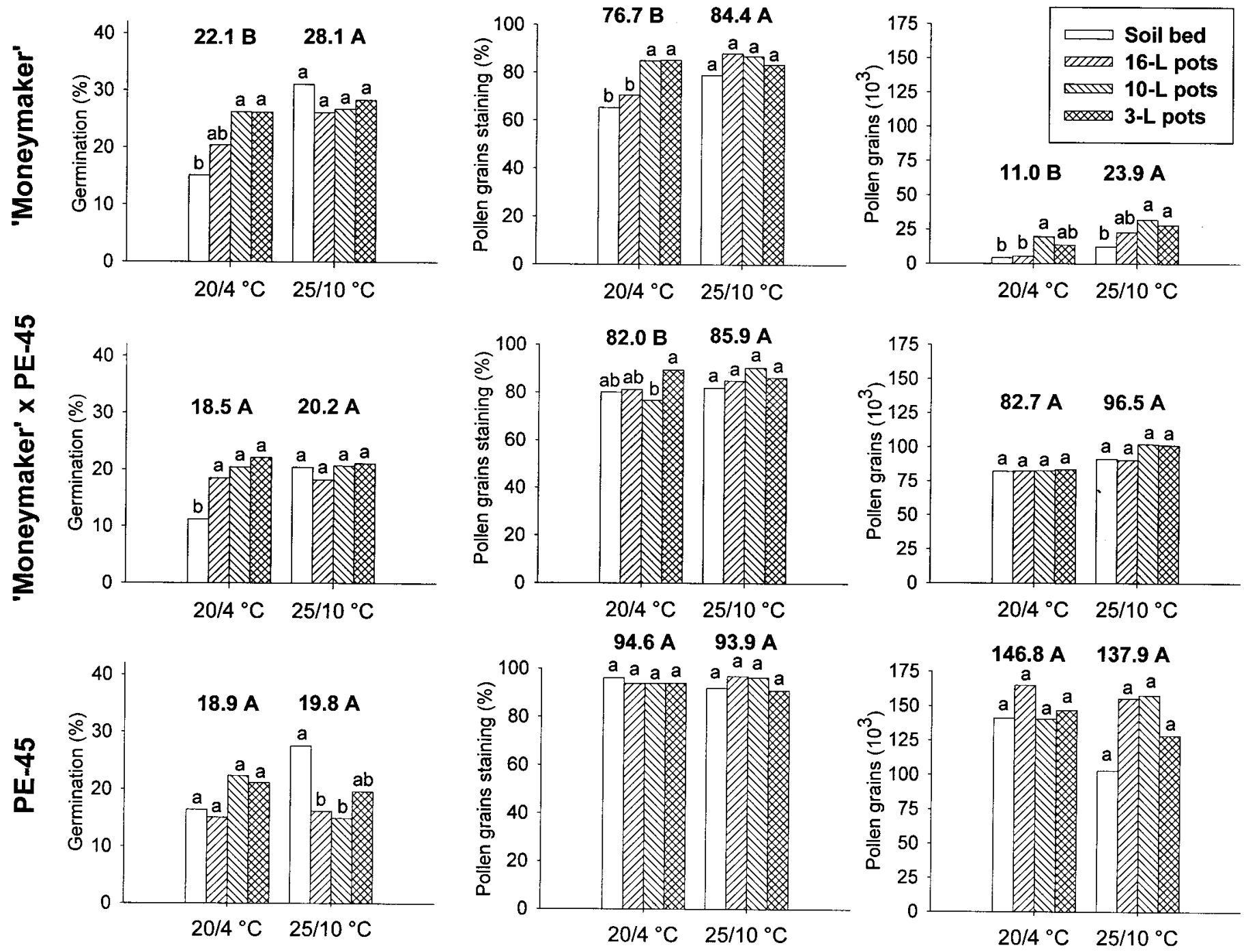

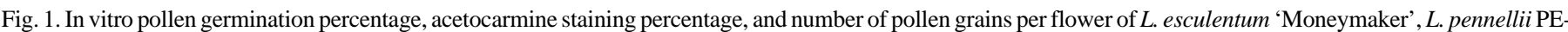

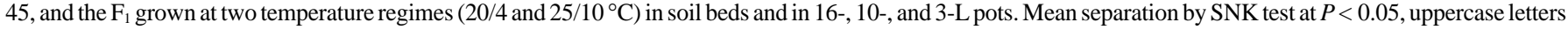

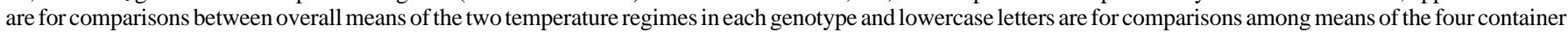
treatments in each genotype and temperature regime. 
Table 3. Means \pm SDs (in parentheses) of pollen tubes that reached halflength and the base of the style after hand pollination of 'Moneymaker' flowers with 'Moneymaker' pollen.

\begin{tabular}{lccc}
\hline \hline $\begin{array}{l}\text { Temp } \\
\text { regime }\end{array}$ & Container & $\begin{array}{c}\text { Half-length } \\
\text { style }\end{array}$ & $\begin{array}{c}\text { Style } \\
\text { base }\end{array}$ \\
\hline $20 / 4{ }^{\circ} \mathrm{C}$ & Soil bed & $0 \mathrm{~b}^{\mathrm{z}}$ & $0 \mathrm{~b}$ \\
& 16-L pot & $0 \mathrm{~b}$ & $0 \mathrm{~b}$ \\
& 10-L pot & $0 \mathrm{~b}$ & $0 \mathrm{~b}$ \\
& 3-L pot & $6.6 \mathrm{a}(4.2)$ & $4.4 \mathrm{a}(3.5)$ \\
$25 / 10{ }^{\circ} \mathrm{C}$ & Soil bed & $127.5 \mathrm{a} \mathrm{(48.6)}$ & $72.9 \mathrm{a}(23.8)$ \\
& 16-L pot & $107.8 \mathrm{ab}(25.4)$ & $68.9 \mathrm{ab}(16.0)$ \\
& 10-L pot & $80.0 \mathrm{bc}(17.0)$ & $58.0 \mathrm{ab}(15.3)$ \\
& 3-L pot & $68.0 \mathrm{c}(24.9)$ & $46.0 \mathrm{~b}(20.7)$
\end{tabular}

$\overline{{ }^{\mathrm{z}} \text { Mean separation within columns for each temperature regime by SNK test }}$ at $P<0.05$.

pollen grains per flower and adequate fruit set requires more than 40,000 (Pressman et al., 1999). As a basis for comparison, an experiment carried out by our research group with 'Moneymaker' in spring under a $28 / 15^{\circ} \mathrm{C}$ regime (Grunberg et al., 1995) produced about 140,000 pollen grains per flower.

'Moneymaker' plants grown in 3 - and 10 -L pots under a $20 / 4{ }^{\circ} \mathrm{C}$ regime produced pollen of similar quality and quantity to those of plants grown in $16-\mathrm{L}$ pots and in a soil bed under the $25 / 10{ }^{\circ} \mathrm{C}$ regime. Consequently, growth in a small container volume was able to overcome completely the negative effects of low night temperature $\left(20 / 4^{\circ} \mathrm{C}\right)$ on quality and quantity of pollen produced by the cold-sensitive tomato cultivar. Slightly suboptimal night temperatures $\left(\approx 10^{\circ} \mathrm{C}\right)$ produced little or no differences in any of the genotypes for in vitro pollen germination and in vivo pollen tube growth, for viability or for pollen quantity. This suggested that lower night temperatures, like $20 / 4{ }^{\circ} \mathrm{C}$ of the refrigerated glasshouse experiment, are needed for the beneficial effect of small container volume on tomato pollen to occur. Two hypotheses for the observed effects of container volume on quality and quantity of pollen produced at low temperatures are possible.

First, plants with root growth restricted by small pot volume might change their pattern of allocation of assimilates and alter other physiological characters in some way to permit the pollen to resist cold stress. Nishizawa and Saito (1998) reported that root-restricted plants increased the nonstructural carbohydrate concentration in tomato shoots and Robbins and Pharr (1988) reported a similar increase in cucumber (Cucumis sativus L.) leaves. This extra supply of assimilates in the shoots is available to the flowers and stimulates increases in pollen quality and pollen quantity. This hypothesis is consistent with observations on tomato plants in states of carbohydrate deficiency resulting from adverse conditions such as severe water stress or very low light. In these, fruit set (Leopold and Scott, 1952) and production of fertile pollen (Howlett, 1936; Saini, 1997) are very poor. Nevertheless, most published studies about root restriction used severely restricted root volumes. For example, volume of the small containers used by Nishizawa and Saito (1998) was only $0.037 \mathrm{~L}$ while their large containers $(2.0$ or $4.8 \mathrm{~L})$ were sizes similar to our small pots $(3 \mathrm{~L})$. Moreover, as pollen was sampled from relatively young plants, in the present experiments the plants were not under severe root restriction. It would be valuable to determine whether an increase in carbohydrate shoot content also occurs in these less-severe root restriction conditions (pots of $\approx 3 \mathrm{~L}$ ) compared with soil bed cultivations.

Second, the observed differences in substrate temperatures among the different container volumes in this work suggest another hypoth- esis to explain the beneficial effect of small pot size. The optimum root temperature for tomato is about $25^{\circ} \mathrm{C}$ (Fujishige et al., 1991). Tomato shoot growth and fruit yield are reduced when root substrates are below $10^{\circ} \mathrm{C}$ or above $30{ }^{\circ} \mathrm{C}$, even when shoots are exposed to normal greenhouse temperatures (Fujishige et al., 1991). Soil temperature influences root growth, root metabolic activity, and root sink strength for photosynthates from the shoot; it also increases mineral nutrient uptake by the roots from the soil (Ali et al., 1994). If a better metabolic state of roots and shoots caused by optimum root-zone temperatures affects pollen development positively, the large increase in root temperature measured in 3-L pots during the day could account partially for the increase in pollen quality and pollen quantity under the $20 / 4^{\circ} \mathrm{C}$ regime. Fluctuating root temperatures in the range of 16 to $8^{\circ} \mathrm{C}$ are more favorable for tomato growth than a constant root temperature around $12{ }^{\circ} \mathrm{C}$ (Ali et al., 1994) which has been attributed to reduced plant metabolism and reduced hormone (cytokinin and gibberellin) transport when root temperatures decrease (Ali et al., 1996). Under the $25 / 10^{\circ} \mathrm{C}$ regime, there were large differences between the 0900 and $1400 \mathrm{HR}$ temperatures measured in the different-sized pots and the soil bed, but in this work, both air and root-zone night temperatures might not have been low enough to affect pollen development negatively. Nevertheless, additional experiments in which root-zone temperature is manipulated and pot volume is kept constant will be required to confirm the root-zone temperature hypothesis.

Additional hypotheses based upon water relations to explain the differences noted may be argued. Care was taken to avoid any drought stress in our experiments and, moreover, young plants were grown in aggregated soil whose physical properties ensured the maintenance of proper soil moisture. However, low temperature is known to greatly decrease water permeability of roots (Kramer, 1983) and plants grown in pots could have been under some degree of water stress compared with cultivation in soil beds because of the lower root-zone temperature during the night in the pots. Nevertheless, amelioration of pollen quality and quantity in pots due to this supposed water deficit seems unlikely as drought stress is reported to affect pollen negatively, especially in cereals (Saini, 1997), but also in tomato (Rahman et al., 1998).

For the sensitive cultivar, Moneymaker, low temperatures were much more restrictive for in vivo pollen germination (Table 3 ) than for in vitro germination (Fig. 1). Fernández-Muñoz et al. (1994) reported that the in vivo method is a very good estimator of the capacity of pollen to fertilize and produce seeds, but in this present work, in the $20 / 4{ }^{\circ} \mathrm{C}$ regime experiment, this method might have underestimated actual pollen fertility. Perhaps, because winter conditions are reported to affect the presence or even the nature of the exudate produced by the tomato stigma necessary for pollen grain hydration and germination (Dickinson and Bonner, 1989), the involvement of the pistil in fecundation should not be discounted.

The larger numbers of pollen tubes in 'Moneymaker' styles from plants grown in the soil bed and in the large pots at $25 / 10{ }^{\circ} \mathrm{C}$ might be explained in part by style diameter. 'Moneymaker' produces medium-sized fruit with two to three loculi that usually contain about 100 seeds. 'Moneymaker' flowers have thin styles and this may limit the number of pollen tubes that can grow in them. Our observations in this and previous experiments indicate that tomato flowers of plants that are grown in small containers are smaller than those of plants grown in larger ones (data not presented) and this could account for the low number of pollen tubes that can reach the ovary when tomato plants are cultivated in small containers under nonlimiting environmental conditions such as those in the polyethylene greenhouse. 
In conclusion, the observed qualitative and quantitative differences in pollen produced at low temperatures by plants grown in soil beds or in pots strongly suggest that special care must be taken when studying parameters related to fruit production under adverse conditions. Special attention should be paid to container volume and root-zone temperatures in experiments designed to identify genotypes with pollen fertile at low temperatures and care must be taken in the selection process designed to introduce cold pollen tolerance into tomato cultivars. We suggest that pots be as large as space in the growth chamber or greenhouse permits to allow results of such experiments to be extrapolated or applied to commercial, crop growing situations.

\section{Literature Cited}

Ali, I.A., U. Kafkafi, Y. Sugimoto, and S. Inanaga. 1994. Response of sandgrown tomato supplied with varying ratios of nitrate/ammonium to constant and variable root temperatures. J. Plant Nutr. 17:2001-2024.

Ali, I.A., U. Kafkafi, I. Yamaguchi, Y. Sugimoto, and S. Inanaga. 1996. Effects of low root temperature on sap flow rate, soluble carbohydrates, nitrate contents and on cytokinin and gibberellin levels in root xylem exudate of sand-grown tomato. J. Plant Nutr. 19:619-634.

Bar-Tal, A., A. Feigin, S. Sheinfeld, R. Rosenberg, B. Sternbaum, I. Rylski, and E. Pressman. 1995. Root restriction and $\mathrm{N}^{-\mathrm{NO}_{3}}$ solution concentration effects on nutrient uptake, transpiration and dry matter production of tomato. Scientia Hort. 63:195-208.

Bar-Tal, A. and E. Pressman. 1996. Root restriction and potassium and calcium solution concentrations affect dry-matter production, cation uptake, and blossom-end rot in greenhouse tomato. J. Amer. Soc. Hort. Sci. 121:649-655.

Boland, A.M., P.H. Jerie, P.D. Mitchell, I. Goodwin, and D.J. Connor. 2000a. Long-term effects of restricted root volume and regulated deficit irrigation on peach: I. Growth and mineral nutrition. J. Amer. Soc. Hort. Sci. 125:135-142.

Boland, A.M., P.H. Jerie, P.D. Mitchell, I. Goodwin, and D.J. Connor. 2000b. Long-term effects of restricted root volume and regulated deficit irrigation on peach:II. Productivity and water use.J. Amer. Soc. Hort. Sci. 125:143-148.

Charles, W.B. and R.E. Harris. 1972. Tomato fruit-set at high and low temperatures. Can. J. Hort. Sci. 52:497-506.

Cooper, A.J. 1972. The influence of container volume, solution concentration, $\mathrm{pH}$ and aeration on dry matter partition by tomato plants in water culture. J. Hort. Sci. 47:341-347.

Dickinson, H.G. and L.J. Bonner. 1989. Pollination, p. 133-157. In: C.J. Wright (ed.). Manipulation of fruiting. Butterworths, London.

Fernández-Muñoz, R. and J. Cuartero. 1991. Effects of temperature and irradiance on stigma exsertion, ovule viability and embryo development in tomato. J. Hort. Sci. 66:395-401.

Fernández-Muñoz, R., J.J. González-Fernández, and J. Cuartero. 1994. Methods for testing the fertility of tomato pollen formed at low temperature. J. Hort. Sci. 69:1083-1088.

Fernández-Muñoz, R., J.J. González-Fernández, and J. Cuartero. 1995a. Variability of pollen tolerance to low temperatures in tomato and related wild species. J. Hort. Sci. 70:41-49.

Fernández-Muñoz, R., J.J. González-Fernández, and J. Cuartero. 1995b. Genetics of the viability of pollen grain produced at low temperatures in Lycopersicon Mill. Euphytica 84:139-144.

Fujishige, N., T. Sugiyama, and R. Ogata. 1991. Effect of root temperature on flower formation and fruit yield of tomatoes. J. Jpn. Soc. Hort. Sci. 60:97-103.

Grunberg, K.A., R. Fernández-Muñoz, and J. Cuartero. 1995. Growth, flowering, and quality and quantity of pollen of tomato plants grown under saline conditions. Acta Hort. 512:484-489.
Hameed, M.A., J.B. Reid, and R.N. Rowe. 1987. Root confinement and its effects on the water relations, growth and assimilate partitioning of tomato (Lycopersicon esculentum Mill.). Ann. Bot. 59:685-692.

Hoagland, D.R. and D.I. Arnon. 1950. The water-culture method for growing plants without soil. Calif. Agr. Expt. Sta. Circ. 347.

Howlett, F.S. 1936. The effect of carbohydrate and of nitrogen deficiency upon microsporogenesis and the development of the male gametophyte in the tomato, Lycopersicon esculentum Mill. Ann. Bot. 50:767-803.

Kramer, P.J. 1983. Water relations of plants. Academic Press, Orlando, Fla. Krizek, D.T., A. Carmi, R.M. Mirecki, F.W. Snyder, and J.A. Bunce. 1985. Comparative effects of soil moisture stress and restricted root zone volume on morphogenetic and physiological response of soybean [Glycine $\max$ (L.) Merr.]. J. Expt. Bot. 36:25-38.

Leopold, A.C. and F.I. Scott. 1952. Physiological factors in tomato fruitset. Amer. J. Bot. 39:310-317.

Liu, A. and J.G. Latimer. 1995. Water relations and abscisic acid levels of watermelon as affected by rooting volume restriction. J. Expt. Bot. 46:1011-1015.

Maisonneuve, B. 1982. Effect d'un traitment à basses températures, en conditions contrôlées, sur la qualité du pollen de tomate (Lycopersicon esculentum Mill.). Agronomie 2:755-764.

Maisonneuve, B. and J. Philouze. 1982. Action des basses températures nocturnes sur une collection variétale de tomate (Lycopersicon esculentum Mill.). II.-Etude de la quantité et de la qualité du pollen. Agronomie 2:453-458.

Martin, F.W. 1959. Staining and observing pollen tubes in the style by means of fluorescence. Stain Technol. 34:125-128.

Mutton, L., B.D. Patterson, and V.O. Nguyen. 1987. Two stages of pollen development are particularly sensitive to low temperature. Tomato Genet. Coop. Rpt. 37:56-57.

Nishizawa, T. and K. Saito. 1998. Effects of rooting volume restriction on the growth and carbohydrate concentration in tomato plants. J. Amer. Soc. Hort. Sci. 123:581-585.

Peterson, T.A., M.D. Reinsel, and D.T. Krizek. 1991a. Tomato (Lycopersicon esculentum Mill. cv. 'Better Bush') plant response to root restriction. I. Alteration of plant morphology. J. Expt. Bot. 42:1233-1240.

Peterson, T.A., M.D. Reinsel, and D.T. Krizek. 1991b. Tomato (Lycopersicon esculentum Mill. cv. 'Better Bush') plant response to root restriction. II. Root respiration and ethylene generation. J. Expt. Bot. 42:12411249.

Picken, A.J.F. 1984. A review of pollination and fruit set in the tomato (Lycopersicon esculentum Mill.). J. Hort. Sci. 59:1-13.

Pressman, E., R. Shaked, K. Rosenfeld, and A. Hefetz. 1999. A comparative study of the efficiency of bumblebees and an electric bee in pollinating unheated greenhouse tomatoes. J. Hort. Sci. Biotechnol. 74:101-104.

Rahman, S.M.L., E. Nawata, and T. Sakuratani. 1998. Effects of temperature and water stress on growth, yield and physiological characteristics of heat-tolerant tomato. Jpn. J. Trop. Agr. 42:46-53.

Reiger M. and F. Marra. 1994. Responses of young peach trees to root confinement. J. Amer. Soc. Hort. Sci. 119:223-228.

Robbins, N.S. and D.M. Pharr. 1988. Effect of restricted root growth on carbohydrate metabolism and whole plant growth of Cucumis sativus $\mathrm{L}$. Plant Physiol. 87:409-413.

Ruff, M.S., D.T. Krizek, R.M. Mirecki, and D.W. Inouye. 1987. Restricted root zone volume: Influence on growth and development of tomato. J. Amer. Soc. Hort. Sci. 112:763-769.

Saini, H.S. 1997. Effects of water stress on male gametophyte development in plants. Sexual Plant Reproduction 10:67-73.

Shivanna, K.R. and B.M. Johri. 1985. The angiosperm pollen: Structure and function. Wiley Eastern Ltd., New Delhi.

Sokal, R.R. and F.J. Rohlf. 1981. Biometry. Freeman, San Francisco. Statistical Package for Social Sciences (SPSS). 1999. SPSS for Windows: Release 9.0.1. SPSS, Inc., Chicago. 